\title{
Material recontextualization: trajectories of a popular design
}

The mood for the imagination and inventiveness in Brazil recreates every moment many other "Brazils" that retakes and reinvent traditions, weaving an amalgamated diversity with festivity and affection among transitions, courage and hope tempered with grace and spontaneity that at the same time reaffirms our identity on every small step of citizenship in the streets, homes and institutions. This "brazilianness" that renews and enriches our culture is highlighted here in this text that focus on the inspiration on curious objects made of recontextualized materials in the main urban centers. It is a world that supports a completely different design that could be labeled as good design in where artifacts gain contours as companions of simple everyday experiences in urban life, while capturing the relationship between individual and object transformed into a predicate of own survival. The aim of this study draws attention to the issue of human material experience, more specifically to the recontextualization processes of waste materials by the less favored categories of major urban centers, where material shortage is identified as a motivating factor for inventiveness of individuals in a real kind of popular design.

The here problematized issue that transfigured the "brazilian way" under an empiricist glimpse, records unusual ways of dealing with situations that arise from lack of materials, from truly spontaneous and intuitive improvised solutions in which objects connect individuals with his own realities according to their unconventional techniques or even from the total absence of them. This approach exposes artifacts and subjects in a mix that provides new directions and renewed reflections on this fantastic physical universe so present in the everyday life of main cities. popular design, material culture, material recontextualization

\section{Introduction}

Fulfilling the goal of highlighting, registering and documenting material production of this "mass that invents" - in an expression adopted by Lina Bo Bardi (1994), this study analyzes the originality of these vernacular creations; identified in a sad example of this gap of the social urban material culture from the use of initiatives merged into the informality and marginality of the consumer society, in that artifacts have their original use subverted into curious assemblages, undergoing combinations and new features additions.

Living, anyway, causes necessities which on the other hand are complied with objects, artifacts or products that through its role linking man to his objectives in order to bring him closer to his results while facilitating, surprising and thrilling. After all, everything around us is artificial, built! We experience the physical world through the manufactured 
objects always filtered by the design processes, whether in their most cultured form or even intuitively made. Objects connect us to the world and to them we are connected.

Shapes, colors and textures keep continuously outlining new and confused material contours in the modern megacities, accelerating fragmentation and establishing the visual chaos in a overwhelming and particular way. In this "real Brazil " (Bardi 1994), several material plans are juxtaposed in an urban mapping with unusual rearticulations. From the modern structures to the paraphernalia and gambiarras', can be noticed the consolidation of contemporary landscapes, set in an visually eclectic universe, contrasted between the latest technology and the total absence of it.

\section{The popular experience}

The aim of this study draws attention to the issue of human material experience, more specifically due the recontextualization processes of waste materials by the less favored categories of brazilian major urban centers, where unfortunately material shortage is identified as a motivating factor for inventiveness of individuals in a real kind of popular design. Unpredictable material results can be observed from people's intuitive reactions that combine simple recontextualized materials in extreme circumstances, to construct their own handmade things for survival.

It is noteworthy that this issue frames an ethnographic look over a harsh brazilian reality that portrays in urban centers unexpected assemblages as predicates of survival. A study with objects like as displayed in this article intends to estimulate a possible development of a new glimpse in continuity to Lina Bo Bardi's vernacular taxonomy, to understand the production of these poetic handmade things.

According to Lina Bo Bardi, the concept of "popular design" was heavily influenced by alternative aspects that the material productions presented, especially regarding to the social relations through them undertaken.

Two large groups were initially classified by Lina between instability and unpredictability in the field of production. The first group categorized from objects of autonomy, interest us due to the approach to the more immediate surroundings of individuals, characterized by everyday life artifacts in a production solely directed to their usage value. The second category, although not being the focus of this study is characterized by objects of subservience often seen as false portraits of a "simple and kind" picture of the peasant, that in the clay figures and stories have stamped their unique exchange value.

The pioneering study developed by Lina was structured based on the binomial of necessity and utilitarism at the same time that established the fundamental criteria which valued the positive side of the objects created with this type of alternative production. These objects outweigh their signic lack carrying something more than mere subjective social values that may reflect the ingenuity of the people to bend and circumvent the multifaceted barriers of necessity in favor of their own survival. 
An own aesthetic exudes of these objects that combine a creative and spartan potential due to a process of transformation of what no longer serves into something useful. This is a result from the reuse, a kind of formal reworking due to the magic of transforming one object into another. These recontextualized objects bring with them the marks of the invention, while denoting the material lack from which they were originated.

Functional traits and links conformed by the industry now constitute a simple heritage of it in their new post-industrial condition, where new uses are experienced forcefully exposing the difficulties and contradictions of the new development model assumed by the country (Fig. 1).

It is a kind of production based on popular knowledge and intuition, forgotten due the rapid process of modernization that the country had to undertake, or, as Lina Bo Bardi wrote, "a world that does not want to renounce the human condition despite its forgetfulness and indifference". (Bardi 1994: 37)

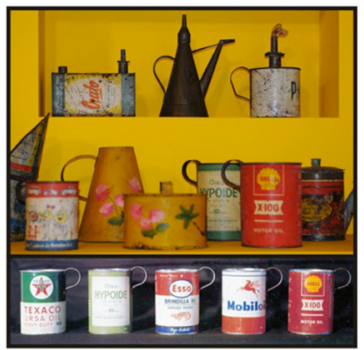

In this sense, when speaking about inventive capacity to create artifacts from available materials, this also reflects the "soul of the people" most presented at popular objects. The popular culture of design closes in the silence of their productions, venting their intelligence through countless pieces scattered on the outskirts of our cities materialized from a rudimentary assemblage where before indistinct industrial products gave rise to a legion of idealized objects developed with non-prescribed rules. Barbecue grills made of truck wheels, buckets built from old refrigerators and pulled by "donkeys-without-tail"; versatile trays, lamps made with scraps of metal packaging apart from a huge variety of toys and instruments of the everyday life constitute the material improvisations that reveal the amazing ability of the simple brazilian to answer his daily needs in an inventive, creatively and picturesque manner. That is the proof that even in times where material culture has incorporated increasingly intangible and decisive rhythm of sounds and digital images, popular knowledge reveal itself as a breath of fresh air in an environment dominated by technological advances. The handcrafted object retains inexorably, in a real or metaphorical way, the authorship of those who made it, such as an artist signing, although not listed his name or brand. It is a sign, not only visible but also palpable.

In the outskirts of main urban centers, reused objects become companions in the experiences of the simple everyday life by providing the rescue of "spontaneity" of a popular and intuitive design that materializes in the most unusual ways and contrasts with the recent available industrial technologies. There are objects developed through empirical and popular knowledge revealing an ingenuity arose from artisanal practices driven by the relentless processes of social exclusion.

Translated by a reality that needs no artificial stimulus to keep on constant motion and
Figure 1. Housewares. Teapots and mugs. Lina Bo Bardi's collection. São Paulo/SP. 
Figure 2. Ambulant barbecue vendor. São Cristóvão/Rio de Janeiro, 2012. Author's photo. carries a unique inventiveness at hand, here builds itself a unique anthropological wealth marked as the starting point for some, in a process that for sure already configured as terminal for many (Fig. 2).

With the intention of joining the creator and his work in an investigation on which there are scant documentary records about its forms and techniques of realization, contrasting objects intuitively created are here identified to compose a portrait of empirical practices that "spontaneously" transcend temporality and confer an unusual vitality to the cities, by featuring a true "spontaneous design", through the materialization of alternative solutions as opposed to the contemporary industrial reality.

The use of such artifacts is provided from creative impulses stimulated by the shortage and privation of individuals who must always draw new strategies to their own survival. The method for creating these unique and improvised objects is constituted by its own absence, strengthening an intuitive and unpremeditated way to plan, characterized by the conditions offered on the streets. In this sense, the necessities of everyday life lead to unusual responses undertaken in this peculiar way of producing artifacts and devices of all kind, set from material compositions and arrangements always loaded with new purposes and intentions.

Tools, instruments, parts, vehicles, cooking utensils and gadgets constitute an unpaired repertoire of unique objects, technically detached from conventional expectations to take forms that reveal the undeniable mark of social exclusion, illustrating emphatically the emblematic phrase printed on the cover-parangolé of Hélio Oiticica (1966): "from adversity we live on".

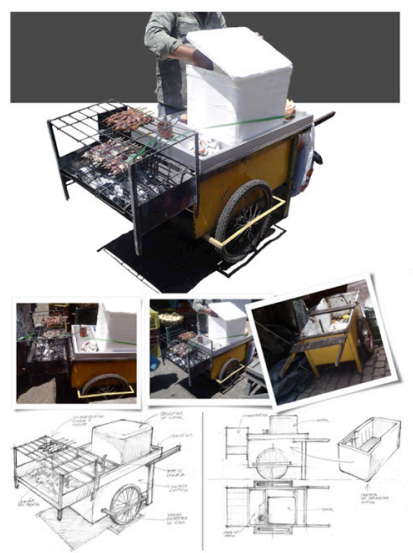

Objects originated from this urban bricolage, sometimes labeled as "intuitive design" or "vernacular design", do not allow their authorial identity, but nevertheless carry the personality of their true authors in a fascinating process of formal invention, constituting the essence of a type of a really popular design. It's the old transforming itself into the new, from the transformation of one object into another, not foreseen in the initial moment of its industrial production.

Deprivation and exclusion does not constitute, per se, a favorable state to the development of human creativity, but this reality shows in a very particular way an 
inherent inventiveness, blatant in our brazilian urban material culture often defined as a "knack" or an original expression of our people.

Victor Papanek in his book Design for the real world (1971), opened the debate on a new paradigm where solutions for product development would need to take into consideration the contemporary harm. Hunger, poverty and racial conflicts redesigns together, in a globally way, the new contours for a different glimpse of the specialized international journals of our brand new designed world. A real-world, concrete, where hung in the air a silent conflict among industrial aesthetics advocated by strands of good design and the true needs of the simple urban man from the disadvantaged social categories. Social function and functionality no longer sought balance for the development of new artifacts for these individuals (Fig. 3).

Real questions about violence, povertv and human degradation increased dramaticallv

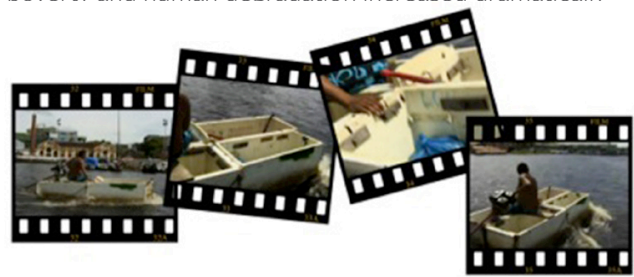

Figure 3.

Boat made with carcasses of refrigerators. Source: Jornal Nacional/TV Globo. Edition of 12/05/2012, 21 h27. Carreiro da Várzea, Codajás/AM. Brazil.

the proportion of actual dissemination of information, by addition of invisible complex mechanisms provided by the latest technologies of the virtual world. The logic of the new shapes needed to include a new understanding to their suitability for new meanings and, above all, new usages. What was yesterday a refrigerator, today may turns into a cargo rig. In other words, the condition of exchange between what is implied on the material and what it can be inferred by human experience characterizes the process of material recontextualization.

The increase of artifacts that integrate the processes of urban disposal is not surprising. Currently consumer goods are so cheap and ubiquitous that it is easier and cheaper to replace them than to fix them. The realization of these difficulties leads to consider as useless a lot of objects that still have significant potential for use.

In a same way that the component substances of objects guide to an uncertain and fathomless future, the material recontextualization outlines a desirable horizon for materiality through initiatives that provide the post-use of objects. This is a posthistory of the artifact that nowadays earns a significant and growing importance by having its projetual trajectory rethought. Ideas are different from objects. According to Flusser (2007), ideas generate objects and these remain in use even if the ideas have been modified. Ideas evolve from the evolution of the objects. The reaction to the existing artifacts are part of the nature of ideas. Objects, in fact, are limited to their own concreteness and can only be worn out or become obsolete. That is the nature of materiality. The power to reframe the artifact belongs to its user. The object does not die but survives.

Over the last fifty years mankind has produced more objects than in all its previous history. As result we run the risk of being burried by the accumulation of discarded things. 
The practice of material recontextualization is common in places where the purchasing power is lower or very restricted. Being attributed new uses after their disposal, objects gain a survival sometimes much longer than the "life" that gave rise to them.

\section{References}

Barbosa, L. (2006) O jeitinho brasileiro: a arte de ser mais igual do que os outros. Rio de Janeiro: Elsevier.

Bardi, L. B. (1994) Tempos de grossura: o design no impasse. São Paulo: Int. Lina Bo e P. M. Bardi.

Dohmann, M. (2013) A experiência material: a cultura do objeto. Rio de Janeiro: Rio Books. Flusser, V. (2007) O mundo codificado: por uma filosofia do design e da comunicação. São Paulo: Cosac Naify.

Moles, A. (1981) Teoria dos objetos. Rio de Janeiro: Tempo Brasileiro.

Pereira, G. (2004) Rua dos inventos: a arte da sobrevivência. Rio de Janeiro: Ouro sobre Azul.

Sudjic, D. (2009) The Language of Things: Understanding the World of Desirable Objects. New York: W.W. Norton \& Company.

Tietmeyer, E., Hirschberger, C., Noack, K., Redlin, J. (2010) Die Sprache der Dinge: kulturwissenschaftliche Perspektiven auf die materielle Kultur. Münster/DE: Waxmann V. GmbH. 